\title{
EQUITY
}

Vol. 24, No.2, 2021, 175-192

DOI: 10.34209 /equ.v24i2.3699

P-ISSN 0216-8545 | E-ISSN 2684-9739

Diunggah : November 2021

Diterima : Januari 2022

Dipublikasi : Januari 2022

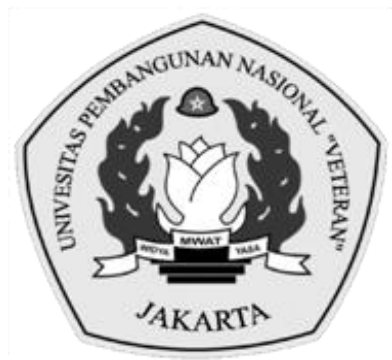

\section{PENGELOLAAN ALOKASI DANA DESA: KOMPETENSI APARATUR DESA, RELIGIUSITAS DAN PENGAWASAN MASYARAKAT}

\author{
Ade Suhartini ${ }^{*}$, Robiati Robiati ${ }^{2}$, Zul Hendri ${ }^{3}$, Decky Hendarsyah ${ }^{4}$ \\ 1adesuhartini5@gmail.com, ${ }^{2}$ robiatieti6@gmail.com, \\ 3hendricks.stiesbks@gmail.com,4deckydb@gmail.com \\ 1,2,3,4Sekolah Tinggi Ilmu Ekonomi Syariah Bengkalis, Indonesia \\ *Penulis Korespondensi
}

\begin{abstract}
Abstrak
Penelitian ini bertujuan untuk menunjukkan pengaruh kompetensi aparatur desa (KAD), religiusitas (RLG), pengawasan masyarakat (PGM) terhadap pengelolaan alokasi dana desa (ADD). Metode penelitian menggunakan pendekatan deskriptif kuantitatif. Sumber data menggunakan data primer dan sekunder berupa angket dan kajian pustaka. Populasi penelitian adalah masyarakat desa Lubuk Gaung, Siak Kecil, Kabupaten Bengkalis, Riau. Pengambilan sampel menggunakan teknik purposive sampling, sehingga diperoleh jumlah sampel sebanyak 50 responden. Analisis data menggunakan pendekatan regresi linear berganda. Namun dilakukan terlebih dahulu pengujian validitas, reliabilitas, normalitas, multikolinearitas dan heteroskedastisitas. Hasil penelitian menunjukkan bahwa KAD dan PGM berpengaruh positif dan signifikan terhadap pengelolaan ADD. Akan tetapi RLG tidak berpengaruh dan tidak signifikan terhadap pengelolaan ADD. Kemudian KAD, RLG dan PGM secara simultan berpengaruh signifikan terhadap pengelolaan ADD. Penelitian ini memiliki kontribusi secara teoritis dan praktis mengenai faktor-faktor yang mempengaruhi pengelolaan ADD.
\end{abstract}

Kata Kunci: Pengelolaan Alokasi Dana Desa; Kompetensi Aparatur Desa; Religiusitas; Pengawasan Masyarakat

\begin{abstract}
This research aims to show the effect of village apparatus competence (VAC), religiosity (RLG), community supervision (CSV) on the management of village fund allocation (VFA). The research method uses a quantitative descriptive approach. Sources of data using primary and secondary data in questionnaires and literature review. The research population is the people of Lubuk Gaung village, Siak Kecil, Bengkalis district, Riau. Sampling using purposive sampling technique to obtain a total sample of 50 respondents. Data analysis used a multiple linear regression approach. However, the validity, reliability, normality, multicollinearity, and heteroscedasticity tests were conducted first. The results showed that VAC and CSV had a positive and significant effect on the management of VFA. However, RLG has no effect and is not significant in the management of VFA. Then VAC, RLG, and CSV simultaneously have a significant effect on the management of VFA. This research has theoretical and practical contributions regarding the factors that influence the management of VFA.
\end{abstract}

Keywords: Village Fund Allocation Management; Village Apparatus Competence; Religiosity; Community Supervision

Mengutip ini sebagai: Suhartini, A, Robiati, R., Hendri, Z., \& Hendarsyah, D. 2021. Pengelolaan Alokasi Dana Desa: Kompetensi Aparatur Desa, Religiusitas Dan Pengawasan Masyarakat. Equity, 24(2), 157-192. doi.org/10.34209/equ.v24i2.3699 


\section{PENDAHULUAN}

Alokasi dana desa (ADD) berbeda dengan dana desa (DD), DD berasal dari pemerintah pusat, sedangkan ADD berasal dari pemerintah daerah. ADD setiap kabupaten/kota di Indonesia memiliki porsi yang berbeda-beda, sesuai dengan kapasitas anggaran yang tersedia di masing-masing kabupaten atau kota minimal sepuluh persen dari dana alokasi umum ditambah dana bagi hasil (Hendri, 2017; Kemendagri RI, 2007, 2014; Presiden RI, 2014). Pengelolaan ADD menjadi hal yang menarik untuk dikaji bagi para peneliti di Indonesia. Hal ini terbukti dalam jangka waktu lima tahun terakhir sudah banyak penelitian yang dipublikasi mengenai pengelolaan ADD di Indonesia, seperti: akuntabilitas pengelolaan ADD di Kecamatan Rogojampi Kabupaten Banyuwangi (Wida et al., 2017); akuntabilitas pengelolaan ADD di Kecamatan Candipuro Kabupaten Lumajang (Farida et al., 2018); efektivitas pengelolaan ADD (Dethan, 2019); akuntabilitas pengelolaan ADD di Sawahlunto Sumatera Barat (Ningsih et al., 2020); akuntabilitas pengelolaan ADD di Desa Tikonu Kecamatan Wundulako Kabupaten Kolaka (Fait et al., 2021). Akan tetapi penelitian tersebut hanya membahas sebatas pengelolaan ADD saja.

Salah satu faktor terpenting dalam melakukan pengelolaan ADD diperlukan kompetensi aparatur desa (KAD) yang baik, agar pengelolaan ADD lebih baik (Pramesti \& Yuwono, 2018). Namun tingkat KAD di desa Lubuk Gaung, Siak Kecil Kabupaten Bengkalis, Riau bisa dikatakan sedang. Hal tersebut menyebabkan banyak opini dari masyarakat yang menyatakan bahwa pengelolaan ADD di desa Lubuk Gaung kurang baik dan kurang transparan. Melakukan pengelolaan alokasi dana desa diperlukan kepedulian, kedisiplinan dan kejujuran dari aparatur desa, dimana hal tersebut dapat tercermin dari tingkat religiusitas aparatur desa, sehingga dapat meminimalisir penyimpangan dalam pengelolaan ADD (Muhaimin, 2021). Supaya pengelolaan ADD dapat terkontrol maka diperlukan partisipasi masyarakat dalam mengawasi jalannya pengelolaan ADD, sebab partisipasi dari masyarakat secara tidak langsung dapat mengawasi penggunaan ADD (Lolowang et al., 2018).

Sejauh ini penelitian mengenai pengelolaan ADD masih minim, namun untuk pengelolaan DD sudah banyak dilakukan oleh para peneliti. Penelitian mengenai pengelolaan ADD atau pengelolaan DD dapat ditinjau dari beberapa faktor yaitu KAD, religiusitas (RLG) dan pengawasan masyarakat (PGM). Dilihat dari faktor KAD, sudah pernah dilakukan penelitian oleh Wahyuni, Indrawati, \& L. (2018); Aziiz \& Prastiti (2019); Puspa \& Prasetyo (2020); Dewi, Nasfi, \& Yuliza (2021). Penelitian tersebut lebih mengkhususkan pada akuntabilitas pengelolaan ADD atau pengelolaan DD. Kemudian dilihat dari faktor RLG, penelitian sudah pernah dilakukan oleh Cahyadi \& Sujana (2020); Muhaimin (2021). Penelitian tersebut lebih mengkhususkan pada kecurangan pengelolaan keuangan desa (KD) atau DD. Selanjutnya dilihat dari faktor partisipasi masyarakat dalam mengawasi atau PGM, penelitian sudah pernah dilakukan oleh Lolowang, Rompas, \& Mambo (2018); Anggraeni \& Yuliani (2019); Masruhin \& Kaukab (2019). Akan tetapi dari semua penelitian tersebut belum ada yang meneliti ketiga faktor tersebut dalam mempengaruhi pengelolaan ADD. Hal tersebut dapat dijadikan sebagai gap penelitian yang membedakan dengan penelitian-penelitian yang sudah ada. 
Setiap pemerintahan desa di Indonesia memiliki karakteristik dan konteks yang berbeda-beda, termasuk kompetensi dan tingkat RLG aparatur desa dalam mengelola ADD serta bagaimana pengawasan dari masyarakat. Oleh sebab itu penelitian ini bertujuan untuk memberikan bukti baru dengan melakukan pengujian pada desa Lubuk Gaung, Siak Kecil, Kabupaten Bengkalis, Riau. Pengujian dilakukan untuk menunjukkan pengaruh KAD, RLG dan PGM terhadap pengelolaan ADD di desa Lubuk Gaung, Siak Kecil, Kabupaten Bengkalis, Riau. Penelitian ini memiliki kontribusi baik secara teoritis dan praktis dalam pengelolaan ADD melalui faktor-faktor yang relevan. Secara teoritis dapat menambah teori baru mengenai faktor-faktor yang mempengaruhi pengelolaan ADD. Secara praktis dapat membantu pemerintah desa dalam meningkatkan pengelolaan ADD melalui pembentukan regulasi mengenai KAD, RLG dan peran aktif PGM. Sehingga pengelolaan ADD bisa menjadi lebih baik ke depannya terutama di desa Lubuk Gaung, Siak Kecil, Kabupaten Bengkalis, Riau.

\section{TINJAUAN PUSTAKA}

\section{Teori Keprilakuan}

Keprilakuan merupakan gambaran bahwa tindakan seseorang ditentukan dari niatnya (Syah et al., 2018). Niat seseorang dapat terpengaruh dari sikap dan subjektivitas masing-masing individu (Ajzen \& Fishbein, 1980). Sikap merupakan perasaan yang dirasakan individu dalam mendukung atau menolak suatu objek yang sedang dihadapi (Ajzen, 1991). Sikap dapat dipengaruhi oleh motivasi dan kapasitas kognitif dari individu (Ajzen \& Fishbein, 2000). Subjektivitas merupakan persepsi dalam membuat keputusan tentang pengaruh sosial dalam suatu perilaku tertentu (Perdana et al., 2018). Perilaku di dunia kerja secara ideal dapat mengadopsi etika sebagai gaya hidup sehingga dapat mendorong hal yang positif (Lindström, 2016). Etika kerja merupakan perilaku yang dipunyai seseorang atau kelompok yang digunakan dalam dunia kerja untuk mencapai tujuan tertentu berlandaskan norma-norma yang ada (Sarjana, 2014).

\section{Pengelolaan Alokasi Dana Desa (ADD)}

Pengelolaan ADD merupakan satu kesatuan dengan pengelolaan KD berasaskan merata dan adil (Kemendagri RI, 2007). Asas merata disebut juga dengan ADD minimal dengan porsi enam puluh persen dari ADD, sedangkan asas adil disebut juga dengan ADD proporsional dengan porsi empat puluh persen dari ADD (Kemendagri RI, 2007). Pelaksanaan kegiatan yang dananya berasal dari ADD, sepenuhnya dilakukan oleh tim pelaksana desa berdasarkan pada peraturan Bupati atau Walikota daerah yang bersangkutan (Kemendagri RI, 2007). Penggunaan anggaran ADD tiga puluh persen untuk belanja aparatur dan operasional pemerintah desa, dan tujuh puluh persen untuk belanja pemberdayaan masyarakat (Kemendagri RI, 2007). Berhubung ADD bagian dari KD maka pengelolaannya harus berasaskan transparansi, akuntabel, partisipatif, responsif, tertib dan disiplin (Hendri, 2017; Kemendagri RI, 2018). Sedangkan indikator pengelolaan ADD terdiri dari penggunaan ADD sesuai dengan peraturan dan perundang-undangan yang berlaku; pembangunan direncanakan, dikelola dan dikendalikan oleh pemerintah desa; informasi penggunaan ADD diberikan secara 
menyeluruh; pembangunan seluruhnya untuk kepentingan masyarakat desa (Nurohman et al., 2019).

\section{Kompetensi Aparatur Desa (KAD)}

Kompetensi dapat dimaknai dengan kemampuan, kecakapan atau keterampilan yang merujuk kepada karakteristik seseorang dalam keberhasilan pekerjaan yang telah dilakukan (Widyatama et al., 2017). Kompetensi merupakan tindakan perilaku yang memerlukan kombinasi dari pengetahuan, sikap, dan kemampuan atau keahlian (Wahyuni et al., 2018). KAD dapat dikategorikan dalam tiga tingkatan yaitu kemampuan dasar, manajemen dan teknis (Eryana, 2018). KAD memiliki indikator yaitu pengetahuan, kemampuan untuk meningkatkan pengetahuan, inisiatif dalam bekerja, keramahan dan kesopanan, keahlian teknis, kemampuan mencari solusi (Mada et al., 2017).

\section{Religiusitas (RLG)}

Religiusitas merupakan hubungan personal dengan sang maha kuasa, maha pengasih dan maha penyayang yaitu Allah SWT, dengan konsekuensi melaksanakan kehendak-Nya dan menjauhi larangannya (Suryadi \& Hayat, 2020, p. 3). Religiusitas pada dasarnya didalam Islam selalu dikaitkan dengan akidah, syariah, dan akhlak. Ketiga hal tersebut dinamakan iman, islam, dan ihsan yang berlandaskan Al-Quran dan Hadits (Muhaimin, 2021). Untuk mengetahui tingkat religiusitas seseorang dapat diukur dari dimensi atau indikator keyakinan, pengetahuan, penghayatan, praktik ibadah, praktik sosial dan perilaku (Mastiyah, 2018).

\section{Pengawasan Masyarakat (PGM)}

Pengawasan merupakan upaya penetapan standar kinerja dalam mendesain sistem umpan balik, melakukan perbandingan kinerja dengan standar yang ada, mendeteksi penyimpangan, dan melakukan perbaikan secara efektif dan efisien (Anggraeni \& Yuliani, 2019). Proses pengawasan dilakukan terhadap suatu kegiatan yang sedang dilaksanakan agar kegiatan tersebut sesuai dengan yang diharapkan, sehingga kesalahan yang telah terjadi dapat diperbaiki dan tidak terulang di kemudian hari (Lolowang et al., 2018). Pengawasan masyarakat memiliki indikator yaitu pengawasan pelaksanaan pekerjaan, pengawasan batasan waktu dalam penyelesaian pekerjaan, pengawasan hasil kerja dan pengawasan umpan balik serta perbaikan (Lolowang et al., 2018).

\section{Hubungan KAD dengan Pengelolaan ADD}

Tingkat KAD yang tinggi akan meningkatkan akuntabel pengelolaan ADD, sehingga kompetensi aparatur desa memiliki hubungan dan pengaruh terhadap pengelolaan ADD (Masruhin \& Kaukab, 2019). Penelitian mengenai KAD terhadap pengelolaan ADD atau pengelolaan DD sudah pernah dilakukan oleh Mada et al. (2017); Umar, Usman, \& Purba (2018); Masruhin \& Kaukab (2019); Umaira \& Adnan (2019); Karim, Lahay, Monoarfa, Adam, \& Suardi (2019); (Atiningsih \& Ningtyas (2019); Tarjo (2019); Aprilya \& Fitria (2020); Yennisa, Wahyuningsih, \& Budiarto (2020); Raharja, Suherman, \& Alamsyah (2020); Diatmika \& Rahayu (2020); Pahlawan, Wijayanti, \& Suhendro (2020); (Pratiwi \& Dewi (2021); 
Heldawati (2021); Sari \& Padnyawati (2021); Zulkifli, Sandrayati, \& Ariani (2021); Hayati \& Amalia (2021); Suryandari \& Pratama (2021) yang menemukan bahwa KAD mempunyai pengaruh terhadap pengelolaan ADD atau pengelolaan DD baik dari segi akuntabilitas, efektivitas maupun keberhasilan sesuai dengan penelitian yang dikaji peneliti. Oleh sebab itu, maka dapat dibentuk hipotesis sebagai berikut:

H1: KAD berpengaruh signifikan terhadap pengelolaan ADD.

\section{Hubungan RLG dengan Pengelolaan ADD}

Tingkat RLG dapat mengontrol perilaku individu dari perilaku yang tidak etis, semakin tinggi tingkat RLG seseorang maka semakin baik dalam melakukan pengelolaan ADD (Giovano et al., 2020). Penelitian mengenai RLG terhadap pengelolaan ADD atau pengelolaan DD sudah pernah dilakukan oleh Cahyadi \& Sujana (2020); Giovano, Wibowo, \& Yanuarisa (2020); Muhaimin (2021); Hayati \& Amalia (2021) yang menemukan bahwa RLG mempunyai pengaruh terhadap pengelolaan ADD atau pengelolaan DD terutama berkaitan dengan kecurangan. Oleh sebab itu, maka dapat dibentuk hipotesis sebagai berikut:

\section{H2: RLG berpengaruh signifikan terhadap pengelolaan ADD.}

\section{Hubungan PGM dengan Pengelolaan ADD}

Partisipasi masyarakat adalah salah satu faktor dalam menentukan berhasil atau tidaknya kegiatan pembangunan atau pengembangan masyarakat desa (Atiningsih \& Ningtyas, 2019). Partisipasi masyarakat dalam bentuk pengawasan bisa menjadi alat kontrol dalam memperkuat akuntabilitas pengelolaan ADD (Mada et al., 2017). Penelitian mengenai partisipasi masyarakat dalam mengawasi atau PGM terhadap pengelolaan ADD atau pengelolaan DD sudah pernah dilakukan oleh Wibisono (2017); Mada et al. (2017); Julianto \& Dewi (2019); Andriani (2019); Umaira \& Adnan (2019); Karim et al. (2019); Atiningsih \& Ningtyas (2019); (Aprilia \& Shauki (2020); Pahlawan (2020); Pratiwi \& Dewi (2021); Heldawati (2021); Sari \& Padnyawati (2021) yang menyatakan bahwa partisipasi masyarakat dalam mengawasi atau PGM mempunyai pengaruh terhadap pengelolaan ADD atau pengelolaan DD. Oleh sebab itu, maka dapat dibentuk hipotesis sebagai berikut:

H3: PGM berpengaruh signifikan terhadap pengelolaan ADD.

\section{METODOLOGI PENELITIAN}

Penelitian ini dilakukan di desa Lubuk Gaung, Siak Kecil Kabupaten Bengkalis, Riau. Penelitian ini dibangun dengan menggunakan metode deskriptif kuantitatif. Populasi penelitian adalah seluruh masyarakat desa Lubuk Gaung, Siak Kecil, Kabupaten Bengkalis, Riau yang berjumlah 1954 orang. Pengambilan sampel menggunakan teknik purposive sampling, dengan kriteria: (a) Memiliki usia minimal 20 tahun dan maksimal 50 tahun, ini berlaku bagi regulator dan praktisi; (b) Memiliki pengetahuan mengenai alokasi dana desa minimal 1 tahun bagi regulator dan praktisi; (c) Pernah mengikuti musyawarah desa yang membahas mengenai alokasi dana desa. Berdasarkan kriteria tersebut didapat jumlah sampel sebanyak 50 responden, dengan rincian: aparatur desa sebanyak 13 orang; kasi 
pemerintahan desa sebanyak 1 orang; tokoh masyarakat sebanyak 6 orang; pendamping desa sebanyak 1 orang; badan permusyawaratan desa sebanyak 5 orang; masyarakat desa sebanyak 24 orang. Sumber data menggunakan data primer dan sekunder berupa angket dan kajian pustaka. Jawaban pertanyaan pada kuesioner menggunakan skala likert dengan rincian: skor 5 untuk sangat setuju; skor 4 setuju; skor 3 kurang setuju; skor 2 tidak setuju; dan skor 1 untuk sangat tidak setuju. Analisis data menggunakan pendekatan regresi linear berganda. Sebelum analisis data dilakukan, terlebih dahulu dilakukan pengujian validitas, reliabilitas, normalitas, multikolinearitas dan heteroskedastisitas.

\section{HASIL DAN PEMBAHASAN}

\section{Data Responden}

Angket disebar kepada 50 responden, dimana semua responden mengembalikan hasil angket dan semua angket dapat diolah. Berdasarkan hasil olahan data angket, responden dapat dikelompokan berdasarkan jenis kelamin, tingkat pendidikan, usia, dan status. Berdasarkan jenis kelamin diperoleh data responden laki-laki 23 orang (46\%) dan perempuan 27 orang (54\%). Berdasarkan tingkat pendidikan diperoleh data responden, dengan tingkat SD 4 orang (8\%), SMP 7 orang (14\%), SMA/SMK 24 orang (48\%), S1 14 orang (28\%), dan S2 1 orang (2\%). Berdasarkan rentang usia diperoleh data responden, usia 20-30 tahun 26 orang (52\%), 31-40 tahun 17 orang (34\%), dan 41-50 tahun 7 orang (14\%). Berdasarkan status diperoleh data responden, status masyarakat 24 orang (48\%), tokoh masyarakat 6 orang (12\%), badan permusyawaratan desa 5 orang (10\%), pendamping desa 1 orang (2\%), aparatur desa 13 orang (26\%), kasi pemerintahan desa 1 orang $(2 \%)$.

\section{Statistik Deskriptif}

Berdasarkan hasil data angket, dapat diukur rata-rata skor dengan kriteria nilai interval, 1,00-1,80 (sangat rendah), 1,81-2,60 (rendah), 2,61-3,40 (sedang), 3,41-4,20 (tinggi), 4,21-5,00 (sangat tinggi) (Sugiyono, 2013, p. 134). Variabel KAD, rata-rata skor menunjukkan angka 4,26 (sangat tinggi), artinya responden ratarata memilih sangat setuju dari pernyataan yang ada. Variabel RLG rata-rata skor menunjukkan angka 3,21 (sedang) artinya responden rata-rata memilih kurang setuju dari pernyataan yang ada. Variabel PGM rata-rata skor menunjukkan angka 4,24 (sangat tinggi) artinya responden rata-rata memilih sangat setuju dari pernyataan yang ada. Sedangkan variabel pengelolaan ADD rata-rata skor menunjukkan angka 4,18 (tinggi) artinya responden rata-rata memilih setuju dari pernyataan yang ada.

\section{Validitas Data}

Validitas data memerlukan nilai $\alpha, \mathrm{n}$ dan df dalam menentukan nilai rtabel, rtabel dicari menggunakan distribusi tabel $r$, sedangkan nilai rhitung diambil dari hasil olahan korelasi. Keputusan data valid diambil jika nilai rhitung > rtabel, sebaliknya tidak valid. Diketahui nilai $\alpha=0,05 ; \mathrm{n}=50 ; \mathrm{df}=\mathrm{n}-2=50-2=48$; jika dilihat pada distribusi tabel $r$ maka diperoleh nilai rtabel 0,279. Berdasarkan hasil 
uji validitas, variabel KAD memiliki nilai rhitung terendah 0,578 dan rhitung tertinggi 0,767. Variabel RLG memiliki nilai rhitung terendah 0,297 dan rhitung tertinggi 0,938. Variabel PGM memiliki nilai rhitung terendah 0,561 dan rhitung tertinggi 0,803. Variabel pengelolaan ADD memiliki nilai rhitung terendah 0,653 dan rhitung tertinggi 0,923 . Hasil rhitung dari semua variabel $>$ rtabel, sehingga dapat dikatakan data angket valid.

\section{Reliabilitas Data}

Reliabilitas data memerlukan nilai cronbach's alpha (CA) dari hasil reliability statistics. Keputusan data reliabel diambil jika nilai CA $>0,60$, sebaliknya data tidak reliabel. Berdasarkan hasil reliability statistics, variabel KAD memiliki nilai CA 0,710. Variabel RLG memiliki memiliki nilai CA 0,653. Variabel PGM memiliki nilai CA 0,676. Variabel pengelolaan ADD memiliki nilai CA 0,848. Hasil nilai CA dari keempat variabel tersebut $>0,60$, maka dapat dikatakan bahwa data angket reliabel.

\section{Normalitas Data}

Pengujian normalitas data pada model regresi bertujuan untuk menentukan apakah nilai residual terdistribusi normal atau tidak. Uji normalitas data menggunakan uji one sample kolmogorov-smirnov dan grafik normal $p$-p plot. Pengambilan keputusan data terdistribusi normal jika nilai asymp. sig pada pengujian $>0,05$ dan sebaran titik pada grafik normal p-plot tersebar mengikuti arah garis diagonal, selain itu data tidak terdistribusi normal. Hasil uji normalitas memperlihatkan bahwa asymp. sig memiliki nilai 0,165, berarti 0,165 > 0,05. Gambar 1 memperlihatkan bahwa titik tersebar mengikuti garis diagonal, sehingga dapat diartikan bahwa data terdistribusi normal.

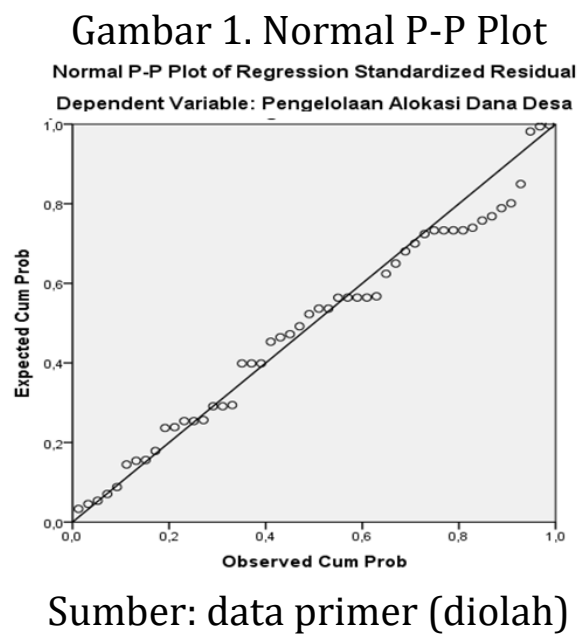

\section{Multikolinearitas}

Pengujian multikolinearitas berguna untuk menguji apakah model regresi memiliki korelasi yang kuat atau tidak antar variabel bebas. Model regresi yang baik seharusnya tidak terdapat korelasi yang kuat antar variabel bebas atau dengan kata lain tidak terdapat gejala multikolinearitas. Pengambilan keputusan multikolinearitas berdasarkan nilai tolerance dan VIF. Jika nilai tolerance $>0,100$ 
dan nilai VIF $<10,00$, maka tidak terjadi multikolinearitas, sebaliknya terjadi multikolinearitas. Hasil pengujian multikolinearitas memperlihatkan bahwa variabel KAD memiliki nilai tolerance 0,184 dan nilai VIF 5,428. Variabel RLG memiliki nilai tolerance 0,853 dan nilai VIF 1,173 . Variabel PGM memiliki nilai tolerance 0,197 dan nilai VIF 5,079. Hasil tersebut menunjukkan bahwa semua variabel bebas memiliki nilai tolerance $>0,100$ dan nilai $\mathrm{VIF}<10,00$, artinya tidak terdapat gejala multikolinearitas antar variabel bebas yang ada.

\section{Heteroskedastisitas}

Pengujian heteroskedastisitas berguna untuk menguji model regresi, apakah terjadi atau tidaknya ketidaksamaan varian dari error untuk setiap variabel bebas. Jika tidak terjadi ketidaksamaan maka disebut dengan homoskedastisitas, sedangkan jika terjadi ketidaksamaan maka disebut dengan heteroskedastisitas. Model regresi yang baik seharusnya tidak terjadi ketidaksamaan varian dari error setiap variabel bebas atau homoskedastisitas. Pengujian heteroskedastisitas dapat dilakukan menggunakan uji glejser. Pengambilan keputusan, jika nilai signifikan $>0,05$ maka tidak terjadi ketidaksamaan (homoskedastisitas), sebaliknya terjadi ketidaksamaan (heteroskedastisitas). Hasil uji glejser memperlihatkan bahwa variabel KAD memiliki nilai signifikan 0,255. Variabel RLG memiliki nilai signifikan 0,912. Variabel PGM memiliki nilai signifikan 0,655. Ketiga variabel menunjukkan bahwa nilai signifikan $>0,05$, berarti tidak terjadi ketidaksamaan (homoskedastisitas).

\section{Regresi Linear Berganda}

Berdasarkan Tabel 1 dapat dibentuk persamaan regresi linier berganda yaitu: $Y=\alpha+\beta 1 X 1+\beta 2 X 2+\beta 3 X 3 ; Y=7,006+0,520 X 1+0,054 X 2+0,933 X 3$, maka bisa dijabarkan bahwa nilai $\alpha$ adalah nilai konstan sebesar 7,006, artinya jika tidak terdapat nilai variabel KAD, RLG dan PGM atau bernilai 0 , maka nilai variabel pengelolaan ADD 7,006. Nilai $\beta 1$ sebagai koefisien pada variabel KAD 0,520, artinya setiap penambahan 1 satuan nilai variabel KAD, maka besar nilai variabel pengelolaan ADD akan bertambah sebesar 0,520, dengan asumsi nilai variabel bebas lainnya tetap. Nilai $\beta 2$ sebagai koefisien pada variabel RLG 0,054, artinya setiap penambahan 1 satuan nilai variabel RLG, maka besar nilai variabel pengelolaan ADD akan bertambah sebesar 0,054, dengan asumsi nilai variabel bebas lainnya tetap. Nilai $\beta 3$ sebagai koefisien pada variabel PGM 0,933, artinya setiap penambahan 1 satuan nilai variabel PGM, maka besar nilai variabel pengelolaan ADD akan bertambah sebesar 0,933, dengan asumsi nilai variabel bebas lainnya tetap.

\section{Hipotesis}

Tabel 1. Coefficients

\begin{tabular}{cc}
\hline Variable & $\alpha / \beta$ \\
\hline Constant & 7,006 \\
KAD & 0,520 \\
RLG & 0,054 \\
PGM & 0,933 \\
\hline \multicolumn{2}{l}{ Sumber: data primer (diolah) }
\end{tabular}


Pengujian hipotesis secara parsial memerlukan nilai ttabel, dimana nilai $\mathrm{n}=$ $50 ; \mathrm{k}=4 ; \alpha / 2=0,05 / 2=0,025 ; \mathrm{df}=\mathrm{n}-\mathrm{k}=50-4=46$, jika dilihat pada distribusi tabel $\mathrm{t}$ maka diperoleh nilai ttabel 2,013. Pengambilan keputusan, jika thitung > ttabel dan signifikan < 0,05 maka terdapat pengaruh yang signifikan antara variabel bebas dengan variabel terikat, sebaliknya tidak ada pengaruh dan tidak signifikan. Tabel 2 memperlihatkan bahwa KAD ? ADD memiliki nilai thitung 5,324 $(5,324>2,013)$ dan nilai signifikan 0,000 $(0,000<0,05)$, berarti terdapat pengaruh yang signifikan antara KAD terhadap pengelolaan ADD (H1 diterima). Kemudian RLG ? ADD memiliki nilai thitung 0,406 $(0,406<2,013)$ dan nilai signifikan 0,686 $(0,686>0,05)$, berarti tidak ada pengaruh dan tidak signifikan antara RLG terhadap pengelolaan ADD (H2 ditolak). Selanjutnya PGM ? ADD memiliki nilai thitung 8,810 $(8,810>2,013)$ dan nilai signifikan $0,000(0,000<0,05)$, berarti terdapat pengaruh yang signifikan antara PGM terhadap pengelolaan ADD (H3 diterima).

Tabel 2. Hasil Hipotesis dan Koefisien Determinasi

\begin{tabular}{llccccc}
\hline & \multicolumn{1}{c}{ Variable } & $t / F$ & Sig. & $R$ & $R^{2}$ & Adj. $R^{2}$ \\
\hline $\mathrm{H}_{1}$ & KAD $\rightarrow$ ADD & 5,324 & 0,000 & 0,609 & 0,371 & 0,358 \\
$\mathrm{H}_{2}$ & RLG $\rightarrow$ ADD & 0,406 & 0,686 & 0,059 & 0,003 & $-0,017$ \\
$\mathrm{H}_{3}$ & PGM $\rightarrow$ ADD & 8,810 & 0,000 & 0,786 & 0,618 & 0,610 \\
& KAD, RLG, PGM $\rightarrow$ ADD & 31,410 & 0,000 & 0,820 & 0,672 & 0,651 \\
\hline
\end{tabular}

Sumber: data primer (diolah)

Pengujian hipotesis secara simultan memerlukan nilai Ftabel, dimana nilai $\mathrm{n}=50 ; \mathrm{k}=4 ; \mathrm{df} 1=\mathrm{k}-1=4-1=3 ; \mathrm{df} 2=\mathrm{n}-\mathrm{k}=50-4=46, \alpha=0,05$, merujuk pada distribusi tabel $\mathrm{F}$ maka didapat Ftabel $=2,810$. Pengambilan keputusan, jika nilai Fhitung > Ftabel dan nilai signifikan < 0,05 maka terdapat pengaruh yang signifikan secara simultan antara variabel bebas dengan variabel terikat, sebaliknya tidak ada pengaruh dan tidak signifikan secara simultan. Tabel 2 memperlihatkan bahwa KAD, RLG, PGM ? ADD memiliki nilai Fhitung 31,410 $(31,410>2,810)$ dan nilai signifikan $0,000(0,000<0,05)$, berarti terdapat pengaruh yang signifikan secara simultan antara KAD, RLG dan PGM terhadap pengelolaan ADD.

\section{Koefisien Determinasi}

Tabel 2 memperlihatkan bahwa KAD ? ADD memiliki nilai R 0,609 dan nilai R2 0,371, berarti antara KAD dengan pengelolaan ADD memiliki tingkat hubungan yang kuat dengan pengaruh sebesar 0,371 (37,1\%). RLG ? ADD memiliki nilai R 0,059 dan nilai R2 0,003, berarti antara RLG dengan pengelolaan ADD memiliki tingkat hubungan yang sangat lemah dengan pengaruh sebesar 0,003 $(0,3 \%)$ dan bisa dikatakan kedua variabel tersebut tidak ada hubungan dan pengaruh. PGM ? ADD memiliki nilai $\mathrm{R}$ 0,786 dan nilai R2 0,618, berarti antara PGM dengan pengelolaan ADD memiliki tingkat hubungan yang kuat dengan pengaruh sebesar 0,618 (61,8\%). KAD, RLG, PGM ? ADD memiliki nilai R 0,820 dan nilai Adjusted R2 0,651 , berarti secara simultan antara KAD, RLG, dan PGM dengan pengelolaan ADD memiliki tingkat hubungan yang sangat kuat dengan pengaruh sebesar 0,651 $(65,1 \%)$. 


\section{Pengaruh KAD Terhadap Pengelolaan ADD}

Hasil penelitian ini menemukan bahwa hipotesis H1 diterima, artinya KAD berpengaruh signifikan terhadap pengelolaan ADD. Berdasarkan Tabel 1, dapat dilihat bahwa nilai koefisien KAD menunjukkan angka positif, berarti KAD berpengaruh positif dan signifikan terhadap pengelolaan ADD, dengan tingkat pengaruh sebesar 37,1\%. Hal tersebut memiliki makna bahwa ketika KAD baik maka pengelolaan ADD juga akan baik. Sebaliknya ketika KAD tidak baik maka pengelolaan ADD juga tidak baik. Hal tersebut sejalan dengan teori keprilakuan bahwa perilaku di dunia kerja secara ideal dapat mengadopsi etika yang baik sehingga dapat mendorong hal yang positif. Hal ini membuktikan bahwa dengan adanya pengetahuan, kemampuan untuk meningkatkan pengetahuan, inisiatif dalam bekerja, keramahan dan kesopanan, keahlian teknis, dan kemampuan mencari solusi yang dimiliki oleh aparatur desa maka pengelolaan ADD akan terlaksana dengan baik.

Hasil penelitian ini didukung oleh penelitian yang telah dilakukan oleh Mada et al. (2017); Umar, Usman, \& Purba (2018); Masruhin \& Kaukab (2019); Umaira \& Adnan (2019); Karim, Lahay, Monoarfa, Adam, \& Suardi (2019); (Atiningsih \& Ningtyas (2019); Tarjo (2019); Aprilya \& Fitria (2020); Yennisa, Wahyuningsih, \& Budiarto (2020); Raharja, Suherman, \& Alamsyah (2020); Diatmika \& Rahayu (2020); Pahlawan, Wijayanti, \& Suhendro (2020); (Pratiwi \& Dewi (2021); Heldawati (2021); Sari \& Padnyawati (2021); Zulkifli, Sandrayati, \& Ariani (2021); Hayati \& Amalia (2021); Suryandari \& Pratama (2021) yang menemukan bahwa KAD berpengaruh terhadap pengelolaan ADD atau pengelolaan DD baik dari segi akuntabilitas, efektivitas maupun keberhasilan sesuai dengan penelitian yang dikaji peneliti. Namun hasil penelitian ini bertolak belakang dengan penelitian yang telah dilakukan oleh Widyatama et al. (2017); Anggraeni \& Yuliani (2019); Heriningsih \& Sudaryati (2019); Indraswari \& Rahayu (2021) yang menemukan bahwa KAD tidak berpengaruh terhadap pengelolaan DD dari segi akuntabilitas.

\section{Pengaruh RLG Terhadap Pengelolaan ADD}

Hasil penelitian ini menemukan bahwa hipotesis H2 ditolak, artinya RLG tidak berpengaruh dan tidak signifikan terhadap pengelolaan ADD. Hasil temuan ini bertentangan dengan teori yang ada yaitu tingkat RLG seseorang dapat mempengaruhi perilaku dan kinerja seseorang. Dimana tingkat RLG seseorang tinggi maka perilaku menyimpang dalam pengelolaan ADD bisa ditekan, sehingga pengelolaan ADD bisa menjadi baik. Namun hasil penelitian ini tidak dapat membuktikan hal tersebut. Walaupun mayoritas masyarakat dan aparatur desa Lubuk Gaung, Siak Kecil Kabupaten Bengkalis, Riau beragama Islam, namun pengelolaan ADD belum ada regulasi tentang penerapan aturan secara syariah atau berdasarkan Al-Quran dan Hadits. Pengelolaan alokasi dana desa di desa Lubuk Gaung, Siak Kecil, Kabupaten Bengkalis, Riau hanya mengikuti dan menyesuaikan dengan pedoman, peraturan dan perundangan-undangan yang berlaku, sehingga tingkat RLG aparatur desa tidak berpengaruh terhadap pengelolaan ADD. Hal ini juga dibuktikan dengan hasil statistik deskriptif data angket mengenai RLG yang menunjukkan bahwa tingkat interval yaitu sedang, 
dimana sebagian responden meyakini bahwa tingkat RLG aparatur desa dalam mengelola alokasi dana desa tidak sepenuhnya berlandaskan Al-Quran dan Hadits. Oleh sebab itu tingkat RLG aparatur desa tidak berpengaruh dan tidak signifikan terhadap pengelolaan ADD.

Hasil penelitian ini sejalan dengan penelitian yang telah dilakukan oleh Indrapraja et al. (2021) yang menemukan bahwa tingkat RLG tidak berpengaruh terhadap kecurangan aparatur sipil negara pada pemerintah provinsi Riau. Kemudian hasil penelitian ini didukung oleh penelitian Heriningsih \& Sudaryati (2019) yang menyatakan bahwa tingkat RLG tidak dapat memediasi good governance dan kompetensi sumber daya manusia, sehingga tidak berpengaruh terhadap pengelolaan DD. Namun hasil penelitian ini bertolak belakang dengan penelitian yang dilakukan oleh Cahyadi \& Sujana (2020); Giovano, Wibowo, \& Yanuarisa (2020); Muhaimin (2021); Hayati \& Amalia (2021) yang menemukan bahwa RLG berpengaruh terhadap pengelolaan DD terutama berkaitan dengan kecurangan.

\section{Pengaruh PGM Terhadap Pengelolaan ADD}

Hasil penelitian ini menemukan bahwa hipotesis H3 diterima, artinya PGM berpengaruh signifikan terhadap pengelolaan ADD. Berdasarkan Tabel 1, dapat dilihat bahwa nilai koefisien PGM menunjukkan angka positif, berarti PGM berpengaruh positif dan signifikan terhadap pengelolaan ADD, dengan tingkat pengaruh sebesar $61,8 \%$. Hal ini mempunyai makna bahwa ketika PGM baik maka pengelolaan ADD akan menjadi baik. Sebaliknya ketika PGM kurang atau tidak ada maka pengelolaan ADD akan menjadi tidak baik. Hal tersebut sesuai dengan teori pengawasan, dimana pengawasan yang dilakukan oleh masyarakat dapat dijadikan umpan balik dari standar proses pengelolaan ADD yang ada. Kemudian masyarakat juga dapat membandingkan dan mendeteksi penyimpangan kinerja dari pengelola, sehingga kinerja pengelola dapat terkontrol sesuai dengan standar yang ada. Jika ada kekurangan dari kinerja pengelola dapat dilakukan perbaikan secara efektif dan efisien. Hal tersebut membuktikan bahwa dengan adanya pengawasan pelaksanaan pekerjaan, pengawasan batasan waktu dalam penyelesaian pekerjaan, pengawasan hasil kerja dan pengawasan umpan balik serta perbaikan maka pengelolaan ADD akan terlaksana dengan baik.

Hasil penelitian ini didukung oleh penelitian yang dilakukan Wibisono (2017); Mada et al. (2017); Julianto \& Dewi (2019); Andriani (2019); Umaira \& Adnan (2019); Karim et al. (2019); Atiningsih \& Ningtyas (2019); (Aprilia \& Shauki (2020); Pahlawan (2020); Pratiwi \& Dewi (2021); Heldawati (2021); Sari \& Padnyawati (2021) yang menemukan bahwa partisipasi masyarakat dalam mengawasi atau PGM berpengaruh terhadap pengelolaan ADD atau pengelolaan DD. Akan tetapi hasil penelitian ini bertolak belakang dengan penelitian yang telah dilakukan oleh Aprilya \& Fitria (2020); Indraswari \& Rahayu (2021) yang menemukan bahwa partisipasi masyarakat dalam mengawasi tidak berpengaruh terhadap pengelolaan DD terutama dari segi akuntabilitasnya.

\section{Pengaruh KAD, RLG, dan PGM Terhadap Pengelolaan ADD}


Hasil penelitian ini menemukan bahwa secara simultan KAD, RLG dan PGM berpengaruh signifikan terhadap pengelolaan ADD. Hal ini mengindikasikan bahwa dengan tingkat KAD, tingkat RLG, dan tingkat PGM yang baik maka akan menghasilkan pengelolaan ADD yang baik juga. Sebaliknya maka pengelolaan ADD tidak akan baik. Hasil penelitian ini menunjukkan bahwa besar pengaruh KAD, RLG dan PGM terhadap pengelolaan ADD secara simultan yaitu sebesar 65,1\%. Hal tersebut menunjukkan bahwa masih ada faktor-faktor lain yang mempengaruhi pengelolaan ADD yaitu sebesar 34,9\%.

Berdasarkan hasil penelitian ini, yang perlu dilakukan ke depannya adalah bagaimana membuat regulasi dan mengimplementasikan langkah-langkah dalam penyempurnaan pengelolaan ADD terutama di desa Lubuk Gaung, Siak Kecil Kabupaten Bengkalis, Riau. Dari segi kompetensi aparatur desa perlu dilakukan seminar, pelatihan dan workshop pengelolaan ADD sehingga KAD dapat meningkat. Kemudian dari segi RLG yang perlu dilakukan adalah pendekatan rohani kepada aparatur desa dan masyarakat seperti mengadakan pengajian rutin dan motivasi-motivasi agamis oleh para pemuka agama, sehingga tingkat RLG aparatur desa dan masyarakat meningkat. Selanjutnya dari segi PGM yang perlu dilakukan adalah mengajak masyarakat agar tetap melakukan pengawasan sesuai dengan norma-norma yang ada karena pengelolaan ADD akan kembali ke masyarakat. Dengan dilakukannya hal tersebut maka pengelolaan ADD akan semakin baik dan masyarakat sendiri yang akan merasakan hasilnya.

\section{SIMPULAN}

Ternyata penelitian ini menunjukkan hasil bahwa KAD dan PGM berpengaruh positif dan signifikan terhadap pengelolaan ADD di desa Lubuk Gaung, Siak Kecil, Kabupaten Bengkalis, Riau. Akan tetapi RLG tidak berpengaruh dan tidak signifikan terhadap pengelolaan ADD di desa Lubuk Gaung, Siak Kecil, Kabupaten Bengkalis, Riau. Secara simultan KAD, RLG dan PGM berpengaruh signifikan terhadap pengelolaan ADD di desa Lubuk Gaung, Siak Kecil, Kabupaten Bengkalis, Riau sebesar 65,1\%.

Hasil penelitian ini menggambarkan bahwa pengelolaan ADD merupakan hal yang sangat penting dalam pembangunan desa dan peningkatan kesejahteraan masyarakat. Oleh sebab itu hasil penelitian ini berimplikasi secara teoritis dan praktis dalam pengelolaan ADD. Secara teoritis dapat menambah teori baru mengenai faktor-faktor yang mempengaruhi pengelolaan ADD. Sedangkan secara praktis dapat membantu pemerintah desa untuk meningkatkan KAD dan partisipasi masyarakat dalam melakukan pengawasan, yang dituangkan dalam suatu regulasi. Regulasi diatur oleh desa, dimana di dalamnya perlu menyatakan bahwa pentingnya peningkatan KAD dan PGM dalam pengelolaan ADD. Sehingga pemerintah desa dan masyarakat desa Lubuk Gaung, Siak Kecil, Kabupaten Bengkalis, Riau dapat memperbaiki dan melengkapi kekurangan-kekurangan yang ada dari segi KAD dan PGM, yang akhirnya dapat meningkatkan pengelolaan ADD menjadi lebih baik.

Penelitian ini memiliki keterbatasan dari segi jumlah variabel penelitian. Kemudian dari segi jumlah sampel juga terdapat keterbatasan yang disebabkan 
oleh pandemi covid-19 dan pembatasan kegiatan masyarakat. Oleh sebab itu penelitian lanjutan perlu dilakukan dengan menambahkan variabel penelitian seperti sistem informasi akuntansi, sistem pengendalian internal, aksesbilitas laporan keuangan, dan komitmen aparatur desa, sebab masih ada ruang sebesar 34,9\%. Kemudian penelitian lanjutan juga bisa menambahkan desa lainnya dan memperbesar jumlah sampel, sehingga data yang diperoleh lebih valid dan dapat mewakili desa-desa yang ada di Indonesia.

\section{DAFTAR PUSTAKA}

Ajzen, I. (1991). The Theory of Planned Behavior. Organizational Behavior and Human Decision Processes, 50(2), 179-211. https://doi.org/10.1016/0749-5978(91)90020-T

Ajzen, I., \& Fishbein, M. (1980). Understanding Attitudes And Predicting Social Behavior. Prentice-Hall.

Ajzen, I., \& Fishbein, M. (2000). Attitudes and the Attitude-Behavior Relation: Reasoned and Automatic Processes. European Review of Social Psychology, 11(1), 1-33. https://doi.org/10.1080/14792779943000116

Andriani, M. (2019). Pengaruh Transparansi, Akuntabilitas, dan Partisipasi Masyarakat terhadap Pengelolaan Dana Desa. JAFA: Journal of Accounting, Finance, and Auditing, 1(2), 1-13. https://doi.org/10.37673/jafa.v1i2.323

Anggraeni, P. D., \& Yuliani, N. L. (2019). Pengaruh Kompetensi Sumber Daya Manusia, Pemanfaatan Teknologi Informasi, Partisipasi Penganggaran, Pengawasan Dan Peran Perangkat Desa Terhadap Pengelolaan Dana Desa (Studi Empiris Pada Desa Se-Kecamatan Kajoran). FEBENEFECIUM: Prosiding 2nd Business and Economics Conference In Utilizing of Modern Techonolgy, 266-284. https://journal.unimma.ac.id/index.php/conference/article/view/3572/

Aprilia, R., \& Shauki, E. R. (2020). Peran Masyarakat dalam Pengawasan Dana Desa. Indonesian Treasury Review Jurnal Perbendaharaan Keuangan Negara Dan Kebijakan Publik, 5(1), 61-75. https://doi.org/10.33105/itrev.v5i1.172

Aprilya, K. R., \& Fitria, A. (2020). Pengaruh Kompetensi, Komitmen Organisasi, Transparansi Dan Partisipasi Masyarakat Terhadap Akuntabilitas Pengelolaan Dana Desa. Jurnal Ilmu Dan Riset Akuntansi (JIRA), 9(3), 1-20. http://jurnalmahasiswa.stiesia.ac.id/index.php/jira/article/view/2829/

Atiningsih, S., \& Ningtyas, A. C. (2019). Pengaruh Kompetensi Aparatur Pengelola Dana Desa, Partisipasi Masyarakat, Dan Sistem Pengendalian Internal Terhadap Akuntabilitas Pengelolaan Dana Desa. JIMAT: Jurnal Ilmu Manajemen Dan Akuntansi Terapan, 10(1), 14-25. https://doi.org/10.36694/jimat.v10i1.182

Aziiz, M. N., \& Prastiti, S. D. (2019). Faktor-Faktor yang Mempengaruhi Akuntabilitas Dana Desa. Jurnal Akuntansi Aktual, 6(2), 334-344. https://doi.org/10.17977/um004v6i22019p334

Cahyadi, M. F., \& Sujana, E. (2020). Pengaruh Religiusitas, Integritas, dan Penegakan Peraturan Terhadap Fraud pada Pengelolaan Keuangan Desa. 
Jurnal Ilmiah Akuntansi Dan Humanika, 10(2), 136-145. https://doi.org/10.23887/jiah.v10i2.25919

Dethan, M. A. (2019). Efektivitas Pengelolaan Alokasi Dana Desa (ADD): Suatu Pendekatan Teoritis. Jurnal Akuntansi: Transparansi Dan Akuntabilitas, 7(1), 15-19. https://doi.org/10.35508/jak.v7i1.1300

Dewi, Y. A., Nasfi, N., \& Yuliza, M. (2021). Internal Control System, Utilization of Accounting Information Technology, On Village Fund Management Accountability. International Journal of Economics, Business and Accounting Research (IJEBAR), 5(1), 190-203. http://jurnal.stieaas.ac.id/index.php/IJEBAR/article/view/2040

Diatmika, I. P. G., \& Rahayu, S. (2020). Kompetensi Perangkat Desa Terhadap Sistem Pengelolaan Dana Desa di Kabupaten Buleleng. Indonesian Journal of Social Sciences and Humanities, 1(4), 215-223. https://journal.publicationcenter.com/index.php/ijssh/article/view/577

Eryana, E. (2018). Keterbatasan Sumber Daya Manusia Terhadap Kinerja Pengelolaan Keuangan Desa. IQTISHADUNA: Jurnal Ilmiah Ekonomi Kita, $7(1)$, 89-95. http://ejournal.stiesyariahbengkalis.ac.id/index.php/iqtishaduna/article/v iew $/ 125$

Fait, T., Septiana, A. R., \& Tohopi, R. (2021). Akuntabilitas Pengelolaan Alokasi Dana Desa (ADD). Sawala: Jurnal Administrasi Negara, 9(1), 102-114. https://doi.org/10.30656/sawala.v9i1.3338

Farida, V., Jati, A. W., \& Harventy, R. (2018). Analisis Akuntabilitas Pengelolaan Alokasi Dana Desa (ADD) Di Kecamatan Candipuro Kabupaten Lumajang. Jurnal Akademi Akuntansi, 1(1), 64-73. https://doi.org/10.22219/jaa.v1i1.6939

Giovano, A., Wibowo, A. S., \& Yanuarisa, Y. (2020). Pengaruh Love Of Money Dan Religiusitas Terhadap Kecenderungan Fraud Accounting Dana Desa Dengan Gender Sebagai Variabel Moderasi Pada Desa Di Kecamatan Katingan Tengah. Jurnal Balance: Media Informasi Akuntansi Dan Keuangan, 12(2), 11-24. https://e-journal.upr.ac.id/index.php/blnc/article/view/1879

Hayati, N., \& Amalia, I. (2021). The effect of religiosity and moderation of morality on fraud prevention in the management of village funds. The Indonesian Accounting Review, 11(1), 105-114. https://doi.org/10.14414/tiar.v11i1.2297

Heldawati, H. (2021). Pengaruh Kompetensi Aparatur Desa, Partisipasi Masyarakat, dan Pemanfaatan Teknologi Informasi Terhadap Akuntabilitas Pengelolaan Dana Desa. KIAFE: Jurnal Kajian Ilmiah Akuntansi, 1(1). https://jurnal.untan.ac.id/index.php/ejafe/article/view/48723

Hendri, Z. (2017). Peranan Alokasi Dana Desa Dalam Meningkatkan Kesejahteraan Desa. JAS (Jurnal Akuntansi Syariah), 1(2), 287-299. https://ejournal.stiesyariahbengkalis.ac.id/index.php/jas/article/view/118

Heriningsih, S., \& Sudaryati, D. (2019). Pengaruh Good Governance Dan Kompetensi Sumber Daya Manusia Terhadap Pengelolaan Dana Desa Dengan Relegiusitas Sebagai Pemoderasi. OPTIMUM: Jurnal Ekonomi \& Pembangunan, $\quad 9(1)$, 61-72. http://journal.uad.ac.id/index.php/OPTIMUM/article/view/11250 
Indrapraja, M. H. D., Agusti, R., \& Mela, N. F. (2021). Pengaruh Gaya Kepemimpinan, Budaya Organisasi, Kompetensi Dan Religiusitas Terhadap Kecurangan (Fraud) Aparatur Sipil Negara. CURRENT: Jurnal Kajian Akuntansi Dan Bisnis Terkini, 2(2), 166-183. https://doi.org/10.31258/jc.2.2.166-183

Indraswari, N. E., \& Rahayu, Y. (2021). Pengaruh Kompetensi Pemerintah Desa, Partisipasi Masyarakat Dan Pemanfaatan Teknologi Informasi Terhadap Akuntabilitas Pengelolaan Dana Desa. Jurnal Ilmu Dan Riset Akuntansi (JIRA), 10(4), 1-15. http://jurnalmahasiswa.stiesia.ac.id/index.php/jira/article/view/3866

Julianto, I. P., \& Dewi, G. A. K. R. S. (2019). Pengaruh Partisipasi Masyarakat, Penggunaan Sistem Keuangan Desa, Kompetensi Pendamping Desa Serta Komitmen Pemerintah Daerah Terhadap Keberhasilan Pengelolaan Dana Desa. Jurnal Ilmiah Akuntansi, 4(1), 24-42. https://doi.org/10.23887/jia.v4i1.17242

Karim, S. A. H., Lahay, M., Monoarfa, Z., Adam, R. P., \& Suardi, S. (2019). Pengaruh Kompetensi Aparat Desa, Komitmen Organisasi Dan Partisipasi Masyarakat Terhadap Keberhasilan Pengelolaan Keuangan Desa (Sudi Kasus Desa Buntongi Kec.Ampana Kota Kab.Tojo Una Una). Agribusiness Journal, 13(2), 18-24. https://doi.org/10.15408/aj.v13i2.13947

Kemendagri RI. (2007). Peraturan Menteri Dalam Negeri Nomor 37 Tahun 2007 Tentang Pedoman Pengelolaan Keuangan Desa. https://peraturan.bpk.go.id/Home/Details/126413/permendagri-no-37tahun-2007

Kemendagri RI. (2014). Peraturan Menteri Dalam Negeri Republik Indonesia Nomor 113 Tahun 2014 Tentang Pengelolaan Keuangan Desa. https://peraturan.bpk.go.id/Home/Details/111736/permendagri-no-113tahun-2014

Kemendagri RI. (2018). Peraturan Menteri Dalam Negeri Republik Indonesia Nomor 20 Tahun 2018 Tentang Pengelolaan Keuangan Desa. https://peraturan.bpk.go.id/Home/Details/139714/permendagri-no-20tahun-2018

Lindström, S. (2016). Artists and Multiple Job Holding-Breadwinning Work as Mediating Between Bohemian and Entrepreneurial Identities and Behavior. Nordic Journal of Working Life Studies, 6(3), 43-58. https://doi.org/10.19154/njwls.v6i3.5527

Lolowang, F. J., Rompas, W. J., \& Mambo, R. (2018). Pengaruh Pengawasan Masyarakat Terhadap Pengelolaan Dana Desa Di Desa Kayuuwi Satu Kec. Kawangkoan Barat. Jurnal Administrasi Publik, 4(56), 1-15. https://ejournal.unsrat.ac.id/index.php/JAP/article/view/19756/

Mada, S., Kalangi, L., \& Gamaliel, H. (2017). Pengaruh Kompetensi Aparat Pengelola Dana Desa, Komitmen Organisasi Pemerintah Desa, dan Partisipasi Masyarakat Terhadap Akuntabilitas Pengelolaan Dana Desa Di Kabupaten Gorontalo. Jurnal Riset Akuntansi Dan Auditing "Goodwill," 8(2). https://doi.org/10.35800/jjs.v8i2.17199

Masruhin, A., \& Kaukab, M. E. (2019). Pengaruh Kompetensi Aparatur, Komitmen Organisasi, Partisipasi Masyarakat, Dan Kejelasan Sasaran Anggaran Terhadap Pengelolaan Dana Desa (Studi Empiris Pada Perangkat Desa Di 
Kecamatan Mojotengah Kabupaten Wonosobo). Journal Of Economic, Business And Engineering (JEBE), 1(1), 118-130. https://ojs.unsiq.ac.id/index.php/jebe/article/view/881

Mastiyah, I. (2018). Religiusitas Siswa Madrasah Aliyah Dan Sekolah Menengah Atas. EDUKASI: Jurnal Penelitian Pendidikan Agama Dan Keagamaan, 16(3), 232-246. https://doi.org/10.32729/edukasi.v16i3.484

Muhaimin, M. (2021). Pengaruh Love Of Money dan Religiusitas terhadap Fraud Accounting Anggaran Dana Desa pada Kecamatan Sinjai Tengah. YUME: Journal of Management, 4(2), 121-133. https://journal.stieamkop.ac.id/index.php/yume/article/view/840

Ningsih, W., Indra Arza, F., \& Fitria Sari, V. (2020). Analisis Akuntabilitas Pengelolaan Alokasi Dana Desa. Jurnal Eksplorasi Akuntansi, 2(4), 35173532. https://doi.org/10.24036/jea.v2i4.300

Nurohman, Y. A., Qurniawati, R. S., \& Hasyim, F. (2019). Dana Desa Dalam Peningkatan Kesejahteraan Masyarakat Pada Desa Wisata Menggoro. Magisma: Jurnal Ilmiah Ekonomi Dan Bisnis, 7(1), 35-43. https://doi.org/10.35829/magisma.v7i1.38

Pahlawan, E. W., Wijayanti, A., \& Suhendro, S. (2020). Pengaruh kompetensi aparatur desa, sistem pengendalian internal, pemanfaatan teknologi informasi dan partisipasi masyarakat terhadap akuntabilitas pengelolaan dana desa. Indonesia Accounting Journal, 2(2), 162-172. https://doi.org/10.32400/iaj.29261

Perdana, A. A., Hasan, A., \& Rasuli, M. (2018). Pengaruh Sikap, Norma Subyektif, Persepsi Kontrol Perilaku dan Etika terhadap Whistleblowing Intention dan Perilaku Whistleblowing (Studi Empiris di BPKP Perwakilan Riau dan Sumatera Barat). Jurnal Akuntansi Keuangan Dan Bisnis, 11(1), 89-98. https://jurnal.pcr.ac.id/index.php/jakb/article/view/1680

Pramesti, F. A., \& Yuwono, T. (2018). Akuntabilitas Pemerintah Desa Dalam Pengelolaan Alokasi Dana Desa Di Desa Temulus Kecamatan Mejobo Kabupaten Kudus. Journal of Politic and Government Studies, 7(2), 131140. https://ejournal3.undip.ac.id/index.php/jpgs/article/view/20049

Pratiwi, P. I., \& Dewi, R. S. (2021). Pengaruh Kompetensi Aparat Desa Dan Partisipasi Masyarakat Terhadap Akuntabilitas Pengelolaan Dana Desa Di Kecamatan Namorambe Kabupaten Deli Serdang. Indonesian Journal of Business Analytics, 1(2), 183-198. https://doi.org/10.54259/ijba.v1i2.69

Presiden RI. (2014). Undang-Undang Republik Indonesia Nomor 6 Tahun 2014 Tentang Desa. https://peraturan.bpk.go.id/Home/Details/38582/uu-no-6tahun-2014

Puspa, D. F., \& Prasetyo, R. A. (2020). Pengaruh Kompetensi Pemerintah Desa, Sistem Pengendalian Internal, Dan Aksesibilitas Laporan Keuangan Terhadap Akuntabilitas Pengelolaan Dana Desa (Studi Pada Pemerintah Desa Di Kota Pariaman). Media Riset Akuntansi, Auditing \& Informasi, 13(1), 281-297. https://doi.org/10.25105/mraai.v20i2.7894

Raharja, A. D., Suherman, A., \& Alamsyah, S. (2020). Pengaruh Kompetensi Sumber Daya Manusia Terhadap Pengelolaan Alokasi Dana Desa (ADD) (Studi Kasus Di Desa Neglasari, Desa Cijangkar, Desa Bojongkalong, Desa Mekarsari, Desa Bojongsari Dan Desa Kertaangsana Kecamatan Nyalindung Kab. Sukabumi 
Jawa Barat). Prosiding Seminar Nasional Manajemen, Ekonomi, Dan Akuntansi, 68-77. https://proceeding.unpkediri.ac.id/index.php/senmea/article/view/231

Sari, N. M. R., \& Padnyawati, K. D. (2021). Pengaruh Kompetensi Aparat Pengelola Dana Desa, Komitmen Organisasi Pemerintah Desa, dan Partisipasi Masyarakat Terhadap Akuntabilitas Pengelolaan Dana Desa. Hita Akuntansi Dan Keuangan, 2(2), 544-562. https://ejournal.unhi.ac.id/index.php/HAK/article/view/1571

Sarjana, S. (2014). Pengaruh Kepemimpinan dan Kerja Sama Tim terhadap Etika Kerja Guru SMK. Jurnal Pendidikan Dan Kebudayaan, 20(2), 234-250. https://doi.org/10.24832/jpnk.v20i2.141

Sugiyono, S. (2013). Metode Penelitian Kuantitatif Kualitatif dan R\&D. Alfabeta.

Suryadi, B., \& Hayat, B. (2020). Religiusitas. Bibliosmia Karya Indonesia.

Suryandari, E., \& Pratama, L. V. (2021). Determinan Fraud Dana Desa: Pengujian Elemen Fraud Hexagon, Machiavellian, dan Love of Money. Reviu Akuntansi Dan Bisnis Indonesia, 5(1), 55-78. https://doi.org/10.18196/rabin.v5i1.11688

Syah, S. R., Ibrahim, I., \& Sufardi, S. (2018). Switching Behavior Nasabah Bank: Tinjauan Empiris Teori Keperilakuan Di Kota Makassar. Ad'ministrare: Jurnal Pemikiran Ilmiah Dan Pendidikan Administrasi Perkantoran, 5(2), 113-122. https://doi.org/10.26858/ja.v5i2.7973

Tarjo, T. (2019). Pengaruh Kompetensi Aparat Desa dan Komitmen Organisasi Terhadap Akuntabilitas Dana Desa. Jurnal Ilmiah Tata Sejuta STIA Mataram, 5(2), 25-41. https://doi.org/10.32666/tatasejuta.v5i2.85

Umaira, S., \& Adnan, A. (2019). Pengaruh Partisipasi Masyarakat, Kompetensi Sumber Daya Manusia, Dan Pengawasan Terhadap Akuntabilitas Pengelolaan Dana Desa (Studi Kasus Pada Kabupaten Aceh Barat Daya). Jurnal Ilmiah Mahasiswa Ekonomi Akuntansi, 4(3), 471-481. https://doi.org/10.24815/jimeka.v4i3.12580

Umar, H., Usman, S., \& Purba, R. B. (2018). The Influence Of Internal Control And Competence of Human Resources On Village Fund Management And The Implications On The Quality Of Village Financial Reports. International Journal Of Civil Engineering And Technology (IJCIET), 9(7), 1525-1531. https://iaeme.com/Home/article_id/IJCIET_09_07_162

Wahyuni, S., Indrawati, N., \& L., A. A. (2018). Pengaruh Sistem Pengendalian Intern, Sistem Informasi Akuntansi, Dan Kompetensi Aparat Terhadap Akuntabilitas Pengelolaan Alokasi Dana Desa: Studi Empiris Desa-Desa Di Kabupaten Rokan Hulu. Jurnal Ekonomi, 26(3), 98-110. https://je.ejournal.unri.ac.id/index.php/JE/article/view/7872

Wibisono, N. (2017). Mengungkap Fenomena Pengawasan Publik Terhadap Dana Desa Di Kabupaten Madiun. Jurnal AKSI (Akuntansi Dan Sistem Informasi), 1(2), 8-19. https://doi.org/10.32486/aksi.v1i2.115

Wida, S. A., Supatmoko, D., \& Kurrohman, T. (2017). Akuntabilitas Pengelolaan Alokasi Dana Desa (ADD) di Desa-Desa Kecamatan Rogojampi Kabupaten Banyuwangi. E-Journal Ekonomi Bisnis Dan Akuntansi, 4(2), 148-152. https://doi.org/10.19184/ejeba.v4i2.5356 
Widyatama, A., Novita, L., \& Diarespati, D. (2017). Pengaruh Kompetensi dan Sistem Pengendalian Internal Terhadap Akuntabilitas Pemerintah Desa dalam Mengelola Alokasi Dana Desa (ADD). Berkala Akuntansi Dan Keuangan Indonesia, 2(2), 1-21. https://doi.org/10.20473/baki.v2i2.4762

Yennisa, Y., Wahyuningsih, S., \& Budiarto, D. S. (2020). Faktor-Faktor Yang Mempengaruhi Akuntabilitas Dana Desa Pada Kecamatan Gamping. Efektif Jurnal Ekonomi Dan Bisnis, 11(1), 49-56. http://www.ejournal.janabadra.ac.id/index.php/jurnalefektif/article/view/1143

Zulkifli, Z., Sandrayati, S., \& Ariani, N. (2021). Pengaruh Kompetensi Aparatur Desa, Sistem Pengendalian Internal Dan Komitmen Organisasi Terhadap Akuntabilitas Pengelolaan Dana Desa Di Kecamatan Muara Enim Kabupaten Muara Enim. JEMBATAN (Jurnal Ekonomi, Manajemen, Bisnis, Auditing, Dan Akuntansi), 6(1), 26-38. https://doi.org/10.54077/jembatan.v6i1.55 